\title{
Effects of Rainfall Regime and its Character Indices on Soil Loss at Loessial Hillslope with Ephemeral Gully
}

\author{
X. Xu' ${ }^{1}$, F. Zheng ${ }^{2}, Y . \operatorname{Han}^{3}$
}

Understanding the relationship between hillslope soil loss with ephemeral gully and rainfall regime is important for soil loss prediction and erosion control. Based on 12-year field observation data, this paper quantified the rainfall regime impacts on soil loss at a loessial hillslope with an ephemeral gully. Rainfall regimes were classified using 115 rainfall events in K-mean clustering and Discriminant analysis, according to the three storm rainfall parameters of precipitation depth (P), rainfall duration (D), and maximum 30-minute rainfall intensity (I30).

The results showed that the 115 rainfall events could be divided into three rainfall regimes and gathered in three concentrated area (Figure 1). Rainfall Regime 1 (RR1) storms had large I30 values with low precipitation

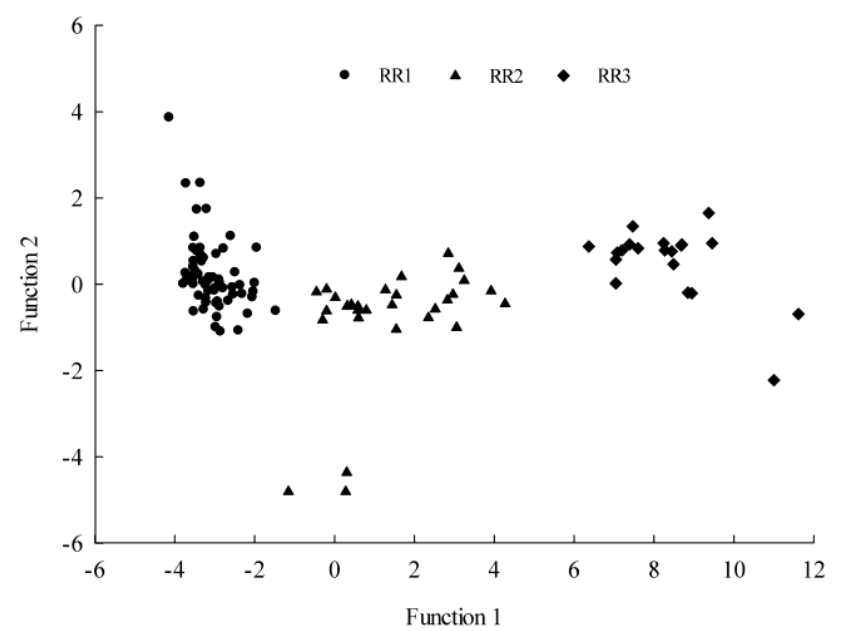

Figure 1. Distribution of the three rainfall regimes by using discriminant analysis based on K-mean clustering. depths and short durations, while the three rainfall parameters of Rainfall Regime 3 (RR3) storms were opposite those of RR1; for Rainfall Regime 2 (RR2) the precipitation depths, durations and I30 values were all between those of RR1 and RR3. RR1 was not only the dominant rainfall regime for causing soil loss on the loessial hillslope with an ephemeral gully, but the observed data for this group also contained a single extremely large event in which soil loss exceeded $8,000 \mathrm{t} \mathrm{km}^{-2}$.

By using Pearson correlation analysis, PI30 was selected as the key index of rainfall characteristics to fit a soil loss equation to account for ephemeral gully erosion with or without rainfall regime classifications, due to its closest relationships with soil loss (Table 1).

Four linear regression equations between soil loss and PI30 were fitted. All equations were significant at the $95 \%$ confidence level.

The soil loss equation without rainfall regime classification was:

$$
\text { TRE }: S L=0.88 P I_{30}+168.02 \quad\left(R^{2}=0.53, n=56\right)
$$

The soil loss equations with rainfall regime classification were:

$$
\begin{cases}R R 1: S L=1.66 P I_{30}-123.81 & \left(R^{2}=0.94, n=30\right) \\ R R 2: S L=0.51 P I_{30}+214.67 & \left(R^{2}=0.82, n=16\right) \\ R R 3: S L=0.23 P I_{30}+146.32 & \left(R^{2}=0.92, n=10\right)\end{cases}
$$

where SL was soil loss for individual rainfall event, and $\mathrm{PI}_{30}$ was the product of $\mathrm{P}$ (precipitation depth) and I30 (maximum 30 min rainfall intensity).

${ }^{1}$ Ximeng Xu, Ph.D. candidate, Northwest A\&F University, Yangling, Shaanxi, China; ${ }^{2}$ Fenli Zheng, Professor, Northwest A\&F University, Yangling, Shaanxi, China; ${ }^{3}$ Yong Han, Ph.D. candidate, Northwest A\&F University, Yangling, Shaanxi, China; Corresponding author: F. Zheng, email: flzh@ms.iswc.ac.cn. 
Compared to equations without rainfall regime classification, the validation results of the equations with rainfall regime classification had satisfactory accuracy (Figure 2), indicating the great necessity to quantify the rainfall regime. The equations of this study could be used to precisely predict the soil loss on a loessial hillslope with an ephemeral gully.

Table 1. Pearson correlation between soil loss and rainfall indices under three rainfall regimes.

\begin{tabular}{cccccccccccc}
\hline $\begin{array}{c}\text { Rainfall } \\
\text { regime }\end{array}$ & $P$ & $I_{10}$ & $I_{15}$ & $I_{30}$ & $I_{60}$ & $I_{\mathrm{m}}$ & $P I_{10}$ & $P I_{15}$ & $P I_{30}$ & $P I_{60}$ & $P I_{\mathrm{m}}$ \\
\hline $\begin{array}{c}\mathrm{RR} 1 \\
\mathrm{n}=65)\end{array}$ & $0.77^{* *}$ & $0.80^{* *}$ & $0.85^{* *}$ & $0.87^{* *}$ & $0.86^{* *}$ & $0.53^{*}$ & $0.87^{* *}$ & $0.89^{* *}$ & $0.90^{* *}$ & $0.88^{* *}$ & $0.83^{* *}$ \\
$\begin{array}{c}\mathrm{RR} 2 \\
(\mathrm{n}=30)\end{array}$ & $0.83^{* *}$ & $0.78^{* *}$ & $0.85^{* *}$ & $0.92^{* *}$ & $0.91^{* *}$ & $0.58^{*}$ & $0.85^{* *}$ & $0.81^{* *}$ & $0.94^{* *}$ & $0.87^{* *}$ & $0.80^{* *}$ \\
$\begin{array}{c}\mathrm{RR} 3 \\
(\mathrm{n}=20)\end{array}$ & $0.77^{* *}$ & $0.86^{* *}$ & $0.81^{* *}$ & $0.91^{* *}$ & $0.86^{* *}$ & $0.58^{*}$ & $0.88^{* *}$ & $0.86^{* *}$ & $0.89^{* *}$ & $0.83^{* *}$ & $0.74 * *$ \\
\hline$* * 204^{*}$ (2)
\end{tabular}

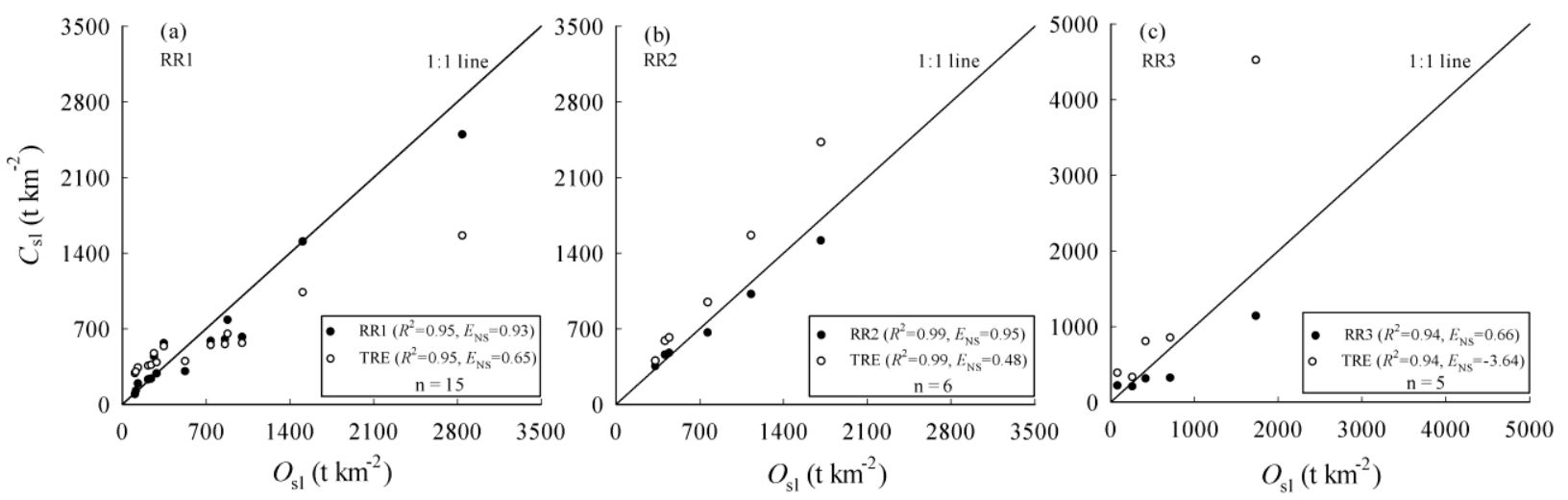

Figure 2. Cross validation of equations for with and without rainfall regime classification under the three rainfall regimes. $\left(\mathrm{C}_{\mathrm{SL}}-\right.$ calculated soil loss; $\mathrm{O}_{\mathrm{SL}}$ - observed soil loss. Solid circles represent soil loss calculated by Eq. (2) under RR1, RR2 and RR3 in which the rainfall events for validation were 15, 6 and 5 times, respectively. The unfilled circles represent soil loss calculated by Eq. (1) and the rainfall events for validation were the same as the former.)

\section{$\underline{\text { References }}$}

Capra, A., and B. Scicolone. 2002. Ephemeral gully erosion in a wheat-cultivated area in Sicily (Italy). Biosys. Engrg. 83: 119-126.

Fang, N.F., Z.H. Shi, L. Li, Z.L. Guo, Q.J. Liu, and L. Ai. 2012. The effects of rainfall regimes and land use changes on runoff and soil loss in a small mountainous watershed. Catena 99(12): 1-8.

James, A.L., and N.T. Roulet. 2009. Antecedent moisture conditions and catchment morphology as controls on spatial patterns of runoff generation in small forest catchments. J. Hydrol. 377(3-4): 351-366. 